\section{Are children with Down's syndrome able to maintain skills learned from a short-term memory training programme?}

\section{Irene Broadley,}

University of Southampton, U.K. John MacDonald and Sue Buckley University Portsmouth, U.K.

\begin{abstract}
The ability of children with Down's syndrome to maintain a set of trained short-term memory skills was assessed by follow up of a group who had previously undergone training in using rehearsal and organisation based memory strategies. That first study (Broadley and MacDonald, 1993) found that training in rehearsal and organisation skills led to an improvement in short-term memory ability in children with Down's syndrome. That study also found that the effects applied across a wide age range; that the training could be conducted effectively by different people and that the type of training (rehearsal or organisation) acts independently, affecting only the targeted memory measures. The study reported here assesses the trained children's short-term memory abilities, 2 months and 8 months after the training had ended. Comparison with their own baseline performance and with a group of untrained children allowed assessment of the long and short term gains in memory performance. It was found that the trained children maintained the level of performance attained at the end of the training study. Training by keyworkers showed advantages for maintenance of some of the gains
\end{abstract}

\begin{abstract}
Acknowledgements
The authors would like to thank the schools and children who took part in this research and also the parents, teachers and classroom assistants who acted as the keyworkers in the training part of the study. This research was supported by a postgraduate bursary from the Portsmouth Down's Syndrome Trust to Irene Broadley.
\end{abstract}

(C) 1993,1999. The Down Syndrome Educational Trust Down Syndrome Research and Practice

1994, 2 (3) 116-122
Introduction

\section{Short-term memory}

The efficiency and development of short term memory (STM) has been the subject of study since the last century. It is widely acknowledged that the ability to store information in STM increases with age and developmental status (Case, Kurland and Goldberg, 1982), although there is some debate as to whether these changes reflect real increases in capacity (Halford and Wilson, 1980) or the development of more sophisticated control processes to use the store more efficiently (Chi, 1977). The importance of STM lies in the role it has in supporting everyday cognitive activity.

A great deal of recent research has investigated the relationship between short term memory operation and vocabulary acquisition, language comprehension and production and reading (Gathercole and Baddeley, 1993). Further support for this role for short-term memory comes from the evidence that links reduced STM functioning and various developmental disorders. Children with severe learning difficulties (Bray, 1979), delayed readers (Nicholson, Fawcett and Baddeley, 1991), speech disordered children (Raine et. al. 1991) and children with Down's syndrome (Bilovsky and Share, 1965) all show short term memory deficits in comparison with normally developing children. There is currently a great deal of research interest in the extent to which the cognitive difficulties these groups experience can be explained by the reduced STM efficiency.

The case of children with Down's syndrome is particularly intriguing. There is evidence that this group show a greater deficit in STM capacity than equivalent mental age matched children with other types of learning difficulty (Marcell and Armstrong, 1982; Mackenzie and Hulme, 1987). To explain why children with Down's syndrome appear to be particularly disadvantaged in their memory span performance Hulme and Mackenzie (1992) used the 'working memory' model (Baddeley and Hitch, 1974). This theory accounts for memory span performance largely in terms of the operation of a speech based component termed the Articulatory Loop. This loop recycles information in working memory through a process of rehearsal. The argument proceeds that the child with Down's syndrome, who typically has auditory processing and speech difficulties, either cannot or does not engage in rehearsal using this loop. This lack of use of rehearsal as a strategy contrasts sharply with normally developing children where it is used from about four years of age (Hitch, Halliday, Dodd \& Littler, 1989).

\section{Training Studies}

If, as is suggested above, the lack of use of rehearsal is a major factor in the memory deficit of children with Down's syndrome then an obvious question that arises is can this be overcome through training and practice. Only a few studies have attempted to test this issue. Hulme and Mackenzie (1992) conducted a study with a group of adolescents with severe learning difficulties and found significantly larger increases in digit span in their trained group than in either of two control groups. The training consisted of a daily 10 minute session, over a ten day period where the subjects repeated successively longer sequences of auditorily presented words. No follow up of the training was conducted.

In a substantially larger study, Broadley and MacDonald (1993) investigated the effectiveness of two memory training 
programmes. One was based on rehearsal as a memory strategy and the other based on the use of chunking and organisation to improve short term memory performance (Herriot and Cox, 1971). In a sample of 25 children with Down's syndrome of mixed age and ability they found that both programmes were effective in raising a range of memory performance measures and that each programme could be demonstrated to only affect the specific memory skills that it was designed to address. The aim of this paper is to follow up that group of trained children 8 months later in order to assess the medium term effectiveness of the training, i.e. to what extent were the gains made maintained. The long term aim of any training is to bring the individual to the point where the material used can be generalised and applied to other tasks with similar demands, or to maintain the strategy in the given task.

The maintenance and durability of learned memory skills Maintenance is defined as "the persistent use of a previously trained strategy on a new task that varies from the old task only in the to-be-learned material while the task demand remains identical." (Burger, Blackman and Tan, 1980, p373). Burger, Blackman and Tan (1980) suggest that maintenance will be achieved if the training includes critical features of active participation; multi-training sessions over several days, analysis of important task components, systematic introduction of the relevant strategies, employment of fading techniques, and impressing subjects with the value of the strategy. To ensure that the person with learning difficulties is successful in maintaining the skills learned the first requirement is that a full and achievable programme should be given. Belmont et al. (1978) stated that although the training programme would not ultimately transfer or generalise, the act of programming would. To effect generalisation to new situations and therefore maintenance of the skill instructional work should directly target self-programming. Belmont concluded that important advances occur when the question of generalisation of programmes is put aside, and the question directly addressed is: "how can people with learning difficulties be trained to invent satisfactory programs for new situations themselves?"

Borkowski and Cavanaugh (1979) argued that strategy maintenance is the first prerequisite for strategy generalisation. If not maintained, a strategy is unlikely to generalise to new settings. Hence conditions that facilitate strategy maintenance (e.g., extended training, active participation by the child, semantic processing, fading of experimenter prompts, and feedback concerning the value of the strategy) are basic to achieving strategy generalisation. The training programmes in the Broadley and MacDonald (1993) study had these characteristics.

Impressive evidence for durability of rehearsal training exists. Brown et al (1974) showed that the effects of training lasted for six months, although later studies have shown that such durability depends upon over-learning and extensive practice in the initial training phase (Borkowski and Cavanaugh, 1979). Such training appears to be highly taskspecific; Brown et al (1974) found that switching from a serial recall task to a probed recall task resulted in the reduction of the trained group of subjects to the level of the untrained group. A critical aspect of maintenance of knowledge is maintaining access to knowledge in memory. Bjorlkund (1987) says "the key to retrieving an item from memory facilitates subsequent retrieval access to that item."

The data described in the previous article (Broadley and MacDonald, 1993) verified that the training produced improvements on the initial memory scores. This article aims at investigating whether the improvements made by July 1992 were maintained at the same level, continued to advance or declined over the succeeding eight months.

\section{Method}

Full details of the intervention and training study from which the data reported here are derived, are described elsewhere (Broadley, 1994; Broadley and MacDonald, 1993). Only details pertaining to the follow up of the study will be covered in this paper.

\section{Subjects}

Subjects were recruited from two geographical areas, through a variety of local contacts. All the children were based at home and attended day school, either a school for children with Severe Learning Difficulties (SLD), moderate learning difficulties (MLD) or their local mainstream school. Parents who consented to their child taking part in the study filled in an initial questionnaire which asked about the child's health, hearing and vision. Teachers completed a record sheet which assessed the child's work at school including assessments on any standardised tests that had been conducted. There were 51 children ( 22 males and 29 females) in the initial sample and they ranged in age from 52 months to 205 months.

\section{Design}

In the original study there was an experimental group $(\mathrm{N}=25)$ who received the memory skills training over two separate six week blocks. There was also a control group $(\mathrm{N}=26)$ who were matched on a group basis in terms of age and ability. In September 1992, eight of the original control group children became part of a replication study on the effectiveness of the memory intervention programme. This left eighteen children in the control group who received no training. This latter group $(\mathrm{N}=18)$ were also followed up and tested at the same time as the trained children and form a comparison control group. This paper will use the data from the experimental group $(\mathrm{N}=25)$ and the remaining control children $(\mathrm{N}=18)$ to assess the extent to which the gains made as a result of the training procedures were maintained over an eight month period.

\section{Procedure}

All the children were assessed on a battery of tests including standardised assessments and measures of short-term memory. These were conducted individually and carried out over a number of sessions but within a short time span. The assessment battery was conducted on four occasions October 1991 - the Baseline measures prior to the training intervention; July 1992 - the Post-test measures immediately after the training had finished; September 1992 - the Post-test measures two months later and March 1993 - the Post-test measures six months later.

\section{Materials}

The tests and measures derived are fully described in the previous paper and will only be briefly reviewed here. They comprised three sets of measures - Rehearsal, Organisation and Word Span. 


\section{Rehearsal}

The measures used were the Picture Memory test and the Verbal Memory test from the McCarthy scales (McCarthy, 1972) and the Visual Recognition test from the British Ability Scales (Elliott et al, 1978).

\section{Organisation}

In the Category Naming task the child was shown a set of pictures and asked to name each object. On successfully completing this the child is then asked to give a single name for all of the objects. One point was given for each category correctly named ( $\max =8$ ). For the Category Oddity task the child was required to choose the object that did not belong to the set, where the set comprised pictures of four objects, three of which came from the same category and one of which did not. The final task here was the Fluency test from the McCarthy scales.

\section{Word Span}

These were standard span tasks with word lists as the stimuli. There were three conditions of presentation: auditory - where the experimenter spoke the words; visual where the experimenter presented pictures of the objects and said the word; and the probe condition - where the child was shown the cards as in the visual condition, but was tested by the experimenter naming an item for which the child had to point to the correct card. All of the cards were face down.

\section{Results}

Since the new control group children were now only a subset of the original control group the first set of analyses are designed to assess the comparability of the trained and 'new' control groups. A series of independent 't' tests were carried out to compare the new control group $(\mathrm{N}=18)$ with the trained group $(\mathrm{N}=25)$ on their baseline scores at the start of the study in October 1991. The means and standard deviations are shown in Tables 1, 2, 3 and 4 . There were only four significant differences between the two groups. Principally on the McCarthy Picture Memory task where the Control group scored significantly higher than the Trained group (2.61 versus 1.36) and the Probe Word Span measures where the Trained group scored significantly and consistently higher than the Control group (see Tables 2 and 3). Thus broadly speaking the trained and control groups were of similar abilities at the start of the study. The Control

\begin{tabular}{|l|l|l|l|}
\hline Trained & General & \multicolumn{2}{|l|}{ Language measures } \\
\hline & BPVT & name 1 & comp 1 \\
\hline $\begin{array}{l}\text { Oct. } \\
1991\end{array}$ & $\begin{array}{l}7.80 \\
(4.02)\end{array}$ & $\begin{array}{l}10.4 \\
(4.16)\end{array}$ & $\begin{array}{l}17.56 \\
(6.11)\end{array}$ \\
\hline July & 8.80 & 11.68 & 21.00 \\
1992 & $(3.79)$ & $(2.99)$ & $(4.93)$ \\
\hline $\begin{array}{l}\text { Sept. } \\
1992\end{array}$ & 8.68 & 11.96 & 20.96 \\
\hline March & $9.79)$ & $(3.20)$ & $(5.02)$ \\
\hline 1993 & $(3.65)$ & 12.56 & 22.00 \\
\hline
\end{tabular}

Table 1a. Means and standard deviations for language and ability measures (raw scores): trained group $(n=25)$.

\begin{tabular}{|l|l|l|l|}
\hline Control & General & \multicolumn{2}{|l|}{ Language measures } \\
\hline & BPVT & name 1 & comp 1 \\
\hline $\begin{array}{l}\text { Oct. } \\
1991\end{array}$ & 8.44 & 10.61 & 20.33 \\
$(2.66)$ & $(2.91)$ & $(5.27)$ \\
\hline $\begin{array}{l}\text { July } \\
1992\end{array}$ & 7.44 & 10.39 & 18.92 \\
\hline $\begin{array}{l}\text { Sept. } \\
1992\end{array}$ & $\begin{array}{l}7.55 \\
(2.15)\end{array}$ & $(2.57)$ & $(3.54)$ \\
\hline $\begin{array}{l}\text { March } \\
1993\end{array}$ & $\begin{array}{l}7.56 \\
(2.09)\end{array}$ & $\begin{array}{l}11.17 \\
(2.04)\end{array}$ & $\begin{array}{l}18.83 \\
(4.39)\end{array}$ \\
\hline
\end{tabular}

Table 1b. Means and standard deviations for language and ability measures (raw scores): control group $(n=18)$.

group was older (119.44 months) than the Trained group (100.28 months) but this difference was not significant $(p>0.05)$.

The Trained and Control groups were also compared on their July 1992 assessments. Tables 1, and 2 show the means and standard deviations of the measures taken. For all tests the Trained group score higher than the Control group. The only measures for which these differences are not significant are the BPVT, the BAS Naming and Comprehension tests and the McCarthy Fluency test.

As would be anticipated, the Trained group are significantly better than the Control group on all the other memory based tasks. This is in line with the results obtained from the analysis of the larger samples. It can be concluded therefore that this 'new' control group are comparable to the original control group and provide a suitable comparison to assess the maintenance of the gains in the trained group.

To assess the degree to which the Trained group were maintaining their advantage over the Control group a series of two-way analysis of variance tests were carried out with Group (Trained versus Control) as an independent factor and Time (July 1992, September 1992, and March 1993) as a repeated measures factor. The results of these analyses are discussed in the sections below.

\begin{tabular}{|l|c|c|c|}
\hline Trained & \multicolumn{2}{|c|}{ Visual memory } & Verbal memory \\
\hline & Pict. 2 & Recog. 1 & Verbal 2 \\
\hline Oct. & $\begin{array}{c}1.36 \\
(1.49)\end{array}$ & $\begin{array}{c}3.28 \\
(2.61)\end{array}$ & $\begin{array}{c}9.32 \\
(5.23)\end{array}$ \\
\hline 1991 & 4.04 & 8.12 & 14.00 \\
July & $(1.39)$ & $(2.49)$ & $(5.12)$ \\
\hline Sept. & 3.96 & 7.40 & 13.72 \\
1992 & $(1.54)$ & $(2.71)$ & $(5.71)$ \\
\hline March & 3.92 & 7.76 & 13.80 \\
1993 & $(1.57)$ & $(3.04)$ & $(6.61)$ \\
\hline
\end{tabular}

Table 2a. Means and standard deviations for the rehearsal measures (raw scores): trained group $(n=25)$. 


\begin{tabular}{|l|l|l|l|}
\hline \hline Control & \multicolumn{2}{|l|}{ Visual memory } & $\begin{array}{l}\text { Verbal } \\
\text { memory }\end{array}$ \\
\hline & Pict. 2 & Recog. 1 & Verbal 2 \\
\hline $\begin{array}{l}\text { Oct. } \\
1991\end{array}$ & $\begin{array}{l}1.67 \\
(1.19)\end{array}$ & $\begin{array}{l}3.11 \\
(1.53)\end{array}$ & $\begin{array}{l}8.67 \\
(4.12)\end{array}$ \\
\hline $\begin{array}{l}\text { July } \\
1992\end{array}$ & $\begin{array}{l}1.83 \\
(1.34)\end{array}$ & $\begin{array}{l}3.61 \\
(2.12)\end{array}$ & $\begin{array}{l}9.78 \\
(3.46)\end{array}$ \\
\hline $\begin{array}{l}\text { Sept. } \\
1992\end{array}$ & $\begin{array}{l}2.61 \\
(1.42)\end{array}$ & $\begin{array}{l}3.89 \\
(2.39)\end{array}$ & $\begin{array}{l}10.39 \\
(4.85)\end{array}$ \\
\hline $\begin{array}{l}\text { March } \\
1993\end{array}$ & $\begin{array}{l}2.55 \\
(0.98)\end{array}$ & $\begin{array}{l}5.06 \\
(1.95)\end{array}$ & $\begin{array}{l}11.39 \\
(3.50)\end{array}$ \\
\hline
\end{tabular}

Table 2b. Means and standard deviations for the rehearsal measures (raw scores): control group $(n=18)$.

\section{Rehearsal measures}

\section{Standardised memory tests:}

The two-way analyses of variance tests showed significant main effects and significant interactions for all three memory measures. Table 2 shows the means and standard deviations for each group at each testing period. Examination of the mean scores reveals that the significant interaction arises from the fact that the Trained group maintains the July 92 level of performance, or decreases only slightly. Paired ' $\mathrm{t}$ ' tests comparing the March 93 means with the July 92 means showed that these decreases were not significant (all $p>0.05)$. On the other hand the Control group increases its level of performance over the same period. The net effect is that the difference between the Trained and Control groups at July 92 is reduced by March 93.

Comparison of the groups at the March 93 testing confirmed that the Trained group still scored significantly $(p<0.05)$ higher than the Control group on the Picture Memory and the Visual Recognition Memory tasks but there was no significant difference between the groups on the Verbal Memory task. Thus it appears that the rehearsal training effect is persisting longer for visually presented materials and tasks than for verbal presentation.

\section{Word span measures:}

Word span performance was measured under different conditions and for words of different lengths. The span score is the longest list that the child could recall correctly in each condition. The means and standard deviations are shown in Table 3. There were a variety of significant effects on these span measures. The general pattern was for significant differences between the groups with the Trained children having higher mean scores than the Control children at all three testing times.

There were also significant effects of Time. In the main this was as a result of poorer performance at the September 92 testing point. Finally there were a number of significant interactions. However, the pattern was not clear. In some cases there was a decrease in the difference between the trained and control children over time (auditory span) whereas in others the effect appeared to be due to an increase in the difference between the trained and control children at the September 92 test (probe span).

\begin{tabular}{|l|l|l|l|}
\hline One syllable & auditory & visual & probe \\
\hline Oct. 1991 & $2.04(0.89)$ & $1.80(0.76)$ & $2.64(0.76)$ \\
\hline July 1992 & $2.68(0.80)$ & $4.40(1.12)$ & $4.52(1.19)$ \\
\hline Sept. 1992 & $3.04(0.54)$ & $3.88(0.97)$ & $3.96(0.84)$ \\
\hline March 1993 & $2.64(0.82)$ & $3.84(1.18)$ & $3.84(1.28)$ \\
\hline Two syllable & & & \\
\hline Oct. 1991 & $1.60(0.82)$ & $1.64(0.64)$ & $2.40(0.87)$ \\
\hline July 1992 & $2.40(0.64)$ & $3.64(1.11)$ & $4.04(0.79)$ \\
\hline Sept. 1992 & $2.68(0.56)$ & $3.52(0.77)$ & $3.68(0.63)$ \\
\hline March 1993 & $2.36(0.70)$ & $3.64(1.11)$ & $3.76(1.27)$ \\
\hline Three syllable & & & \\
\hline Oct. 1991 & $1.24(0.83)$ & $1.40(0.64)$ & $2.16(0.85)$ \\
\hline July 1992 & $2.32(0.90)$ & $3.16(1.29)$ & $3.84(0.89)$ \\
\hline Sept. 1992 & $2.28(0.54)$ & $2.76(0.66)$ & $3.24(0.59)$ \\
\hline March 1993 & $2.32(0.90)$ & $3.36(1.28)$ & $3.68(1.41)$ \\
\hline
\end{tabular}

Table 3a. Means and standard deviations for the word-span measures (raw scores): trained group $(n=25)$

\begin{tabular}{|l|l|l|l|}
\hline One syllable & auditory & visual & probe \\
\hline Oct. 1991 & $2.11(0.68)$ & $2.00(0.91)$ & $2.56(0.94)$ \\
\hline July 1992 & $2.11(0.66)$ & $2.22(0.65)$ & $2.56(0.62)$ \\
\hline Sept. 1992 & $1.78(0.73)$ & $2.00(0.89)$ & $1.94(0.42)$ \\
\hline March 1993 & $2.28(0.46)$ & $2.00(0.80)$ & $2.11(0.32)$ \\
\hline Two syllable & & & \\
\hline Oct. 1991 & $1.61(0.61)$ & $1.78(0.65)$ & $2.22(0.94)$ \\
\hline July 1992 & $1.89(0.58)$ & $1.94(0.65)$ & $2.33(0.69)$ \\
\hline Sept. 1992 & $1.55(0.51)$ & $1.61(0.50)$ & $1.72(0.46)$ \\
\hline March 1993 & $1.94(0.54)$ & $2.06(0.42)$ & $2.00(0.00)$ \\
\hline Three syllable & & & \\
\hline Oct. 1991 & $1.33(0.68)$ & $1.39(0.61)$ & $1.72(0.74)$ \\
\hline July 1992 & $1.61(0.61)$ & $1.56(0.51)$ & $1.72(0.74)$ \\
\hline Sept. 1992 & $1.33(0.59)$ & $1.33(0.59)$ & $1.50(0.51)$ \\
\hline March 1993 & $1.39(0.50)$ & $1.67(0.59)$ & $1.78(0.43)$ \\
\hline
\end{tabular}

Table 3b. Means and standard deviations for the word-span measures (raw scores): control group $(n=18)$.

Comparison of the groups at the March 93 point revealed that the Trained group remained significantly better than the Control group on all measures $(p<0.05)$, but that the size of the effects was larger for the Visual and Probe tasks than for the Auditory presentation. 


\section{Organisation measures}

Table 4 shows the means and standard deviations of the organisation based memory measures across the time span of the study. The two-way analysis of variance tests (Group (Trained v Control) by Month (July, Sept and March) run on the organisation measures showed significant main effects of Group for the Categorisation Naming and Oddity tasks with the Trained group performing better than the Control group. Although the same pattern was found for the Fluency task the difference was not significant. There were significant effects of Time on all three measures and significant interactions between Group and Time again on all three measures. As in the other memory measures the effect of the interaction is that there is a decrease in the difference between the Trained and Control groups from July 92 to March 93.

Paired comparison of the Trained groups' July 92 and March 93 scores showed that there was no significant difference between the two time periods. Thus the performance gains made by the trained children was maintained over the eight month gap. Further, comparison of the groups in March 93 showed that the Trained group had significantly higher scores $(p<0.05)$ than the Control group on the Categorisation Naming and Oddity Tasks but there was no difference between them on the Fluency measure.

\begin{tabular}{|l|l|l|l|}
\hline & \multicolumn{3}{|c|}{ Organisation measures } \\
\hline & $\begin{array}{l}\text { category } \\
\text { name }\end{array}$ & $\begin{array}{l}\text { category } \\
\text { odd }\end{array}$ & $\begin{array}{l}\text { fluency } \\
2\end{array}$ \\
\hline Oct. & 1.80 & 2.32 & 8.20 \\
1991 & $(2.12)$ & $(2.39)$ & $(8.68)$ \\
\hline July & 4.68 & 5.56 & 16.00 \\
1992 & $(3.21)$ & $(2.21)$ & $(10.50)$ \\
\hline Sept. & 3.88 & 4.80 & 15.88 \\
1992 & $(2.79)$ & $(3.07)$ & $(8.95)$ \\
\hline March & 4.60 & 5.40 & 16.08 \\
1993 & $(2.96)$ & $(2.22)$ & $(7.45)$ \\
\hline
\end{tabular}

Table 4a. Means and standard deviations for the organisation measures: trained group $(n=25)$.

\begin{tabular}{|l|l|l|l|}
\hline & \multicolumn{3}{|c|}{ Organisation measures } \\
\hline & $\begin{array}{l}\text { category } \\
\text { name }\end{array}$ & $\begin{array}{l}\text { category } \\
\text { odd }\end{array}$ & $\begin{array}{l}\text { fluency } \\
2\end{array}$ \\
\hline Oct. & 1.17 & 2.17 & 10.11 \\
1991 & $(1.69)$ & $(2.68)$ & $(7.44)$ \\
\hline July & 1.66 & 2.22 & 11.22 \\
1992 & $(1.57)$ & $(2.02)$ & $(7.69)$ \\
\hline Sept. & 1.61 & 1.89 & 11.55 \\
1992 & $(1.85)$ & $(2.05)$ & $(6.92)$ \\
\hline March & 2.17 & 2.39 & 12.28 \\
1993 & $(1.62)$ & $(2.15)$ & $(6.77)$ \\
\hline
\end{tabular}

Table 4b. Means and standard deviations for the organisation measures: control group $(n=18)$.

\section{Summary and discussion}

Overall the data indicate that the improvements made as a result of the memory training programmes are being maintained for the trained group. The final results in March 1993 are significantly different from the October 1991 data and not different from the July 1992 performance. In general, the Control group slowly improved over the year and a half in which they were assessed and narrowed the gap between themselves and the Trained children. However, the Trained children did sustain a significant advantage on visually oriented tasks. What needs some explanation and consideration is why the trained children did not maintain the gap between themselves and the control group.

Several of the scores for the Trained and Control groups declined and then rose again. This was specially apparent at the September 1992 testing point. This coincided with the end of the summer vacation period when the children would have had no contact with the school system. Guralnick (1990) describes the difficulties of assessing the skills for children with Learning Difficulties as "delayed children exhibit an atypical developmental pattern. Cross-sectional studies have shown that, though gains in peer interactions occur across a school year, there is a substantial decline when the summer intervenes or new classmates are introduced". Many teachers also express concern as after the summer holidays children often forget many skills learned during term time. This appears to have been what has happened here.

\section{Maintenance according to the type of trainer: differences between the keyworkers and experimenter}

In the original intervention study the training was carried out with each child either by experimenter $(\mathrm{N}=15)$ or by a keyworker $(\mathrm{N}=10)$. It was anticipated that there might be differences between these two groups and that the keyworker-trained group might retain the memory skills better than those trained by the experimenter. This was based on the idea that as the keyworker was with the child on a constant basis and could be in a position to remind and prompt the child to use the skills learned after the training had ceased. To assess the effect of keyworker or experimenter on the maintenance of the performance gains a series of analyses were conducted.

Initially, in October 1991 on the baseline data there were several differences between the keyworker and the experimenter trained groups. As reported in the previous paper the children trained by keyworkers were more able on a number of the general ability measures taken. Thus although the keyworker trained group were also higher on most of the memory measures, they were only significantly better on the 3-syllable probe condition and the Category Naming measure. However by the end of the training in July 1992 there was only one significant difference between the groups, i.e. that for Verbal memory, in which the keyworker trained group did better $(t=2.17, d f=23, p=.040)$.

\section{September 1992}

The experimenter-trained group were compared with the keyworker-trained group on each measure at September 1992, using independent ' $\mathrm{t}$ ' tests. It was found that the keyworker-trained group were marginally significantly better on two measures. These were the McCarthy Verbal 
Memory task $(\mathrm{t}=2.13 ; \mathrm{d} . \mathrm{f} .=23 ; \mathrm{p}<0.05)$ and the Fluency task $(t=2.08 ;$ d.f. $=23 ; p<0.05)$.

\section{March 1993}

There were several significant differences between the keyworker and experimenter-trained groups on the final March 1993 scores. The keyworker-trained group had significantly higher scores on six of the measures than the experimenter-trained group. These are listed in Table 5 which shows the mean values for each of the two groups on the March 1993 data and the significance level of the difference.

\begin{tabular}{|l|l|l|l|l|}
\hline TEST & $\begin{array}{l}\text { key } \\
\text { worker }\end{array}$ & $\begin{array}{l}\text { experi- } \\
\text { menter }\end{array}$ & $\mathbf{p =}$ & $\mathbf{t =}$ \\
\hline Verbal Memory & 17.0 & 11.7 & .045 & 2.12 \\
\hline $\begin{array}{l}\text { Categorisation } \\
\text { name }\end{array}$ & 6.1 & 3.6 & .035 & 2.24 \\
\hline Visual span 2-syll & 4.2 & 3.3 & .037 & 2.21 \\
\hline Visual span 3-syll & 4.0 & 2.9 & .039 & 2.18 \\
\hline Probe 2-syll & 4.4 & 3.3 & .036 & 2.22 \\
\hline Probe 3-syll & 4.4 & 3.2 & .033 & 2.26 \\
\hline
\end{tabular}

Table 5. Significant differences in March 1993 between the keyworker and experimenter-trained groups ( $d f=23$ for all tests).

Although these differences between the trainers exist it is the case that the experimenter-trained children also continued to improve on several of the tasks. Thus although there is some evidence that the continuing involvement of the trainer will have an effect on the gains made, it is not conclusive. In this study the experimenter also gave feedback to the parents and the schools (through workshops) about the training programmes and it is likely that these people carried on the tasks picking up on and continuing to encourage the children to use the skills learned on an informal basis.

\section{Conclusions}

This paper has evaluated the ability of a trained group of children to maintain the performance achieved during the intervention phase of the study. The data from a comparable control group was also longitudinally analysed to assess whether different gains were made between the control and trained groups. This also enabled comparison of the children's ability to maintain the training. The data indicate that the trained children were able to maintain the skills learned. Burger, Blackman and Tan (1980) found long-term maintenance for a sorting and retrieval strategy after six months for a training programme for individuals with learning difficulties. Brown, Campione and Murphy (1974) also found a similar result. Therefore, the finding from this study fits with these previous ones. This effect could be due to the fact that long periods of training were involved and that the keyworkers had a high interest in the project. Also systematic introduction of the relevant strategies was incorporated in both training programmes. These are factors which may have helped the children to be able to retain the information over the time tested.

A factor that had some effect on the maintenance for the children involved in the memory training programme was the type of trainer they had. Children trained by a keyworker retained the information to a higher degree than that of the experimenter-trained group. However, there were other factors that might have accounted for this significant difference. Several children in the keyworker-trained group $(n=7)$ attended mainstream schools, two attended MLD schools and the one who attended an SLD had a very stimulating home-background, meaning that school-type could have been an influential factor. However, the results from these analyses are confounded as all the children trained by the experimenter attended special schools. The fact that all the keyworkers were volunteers could also affect the outcome. Children trained by keyworkers and those who attended mainstream schools would be expected to be able to maintain the memory strategies most effectively, since recent research by Casey et al., (1988) indicate that these factors have significant beneficial effects for the development of the child with Down's syndrome.

\section{References}

Baddeley,A.D., \& Hitch,G. (1974) Working memory. In G. H. Bower (Ed.), The psychology of learning and motivation (Vol. 8, pp. 47-90). New York: Acadmic Press

Belmont,J.M., Butterfield,C.E. \& Borkowski,J.G. (1978) Training retarded people to generalise memorisation methods across memory tasks. In M.M. Grunneberg. P.E. Morris and R.N. Skyes (Eds.) Practical Aspects of Memory. New York: Academic Press.

Bilovsky,D. \& Share,J. (1965) The ITPA and Down's syndrome: an exploratory study. American Journal of Mental Deficiency, 70, 72-82.

Bjorklund,D. (1987) How age changes in knowledge base contribution to the development of children's memory: an interpretative review. Developmental Review, 7, 93-130.

Borkowski,J.G., and Cavanagh,J.C. (1979) Maintenance and generalisation of skills and strategies by the retarded. In N.R. Ellis (Ed.). Handbook of Mental Deficiency (2nd ed.). Hillsdale, N.J.: Lawrence Erlbaum Associates Inc.

Bray,M. (1979) Strategic production in the retarded. In N.R. Ellis (Ed) Handbook on Mental Deficiency: Psychological Theory and Research (2nd ed.,) Hillsdale, N.J.: Erlbaum.

Broadley,I.W. (1994) Teaching Short-term Memory Skills to Children With Down's Syndrome. (Unpublished PhD thesis, University of Portsmouth, Portsmouth, UK).

Broadley,I.W. and MacDonald,J. (1993) Teaching shortterm memory skills to children with Down's syndrome.Down's Syndrome: Research and Practice, 1, 56-62.

Brown,A.L., Campione,J.C., and Murphy,M.D. (1974) Keeping track of changing variables: Long term retention of a trained rehearsal strategy by retarded adolescents. American Journal of Mental Deficiency, 78, 446-453.

Burger,A.L., Blackman,L.S., \& Tan,N. (1980) Maintenance and generalisation of a sorting and retrieval strategy by EMR and non-retarded individuals. American Journal of Mental Deficiency, 84 (4), 373-380.

Case,R., Kurland,M.D. \& Goldberg,J. (1982) Operational efficiency and the growth of short term memory span.Journal of Experimental Child Psychology, 33, 386-404.

Casey,W., Jones,D., Kurgler,B. and Watkins,B. (1988) Integration of Down's syndrome children in the primary school. British Journal of Educational Psychology, 58, 279286.

Chi, M. (1977) Age differences in memory span. Journal of Experimental Child Psychology, 23, 226-281.

Dunn,L.M., \& Dunn,L.M.L.(1982)British Picture Vocabulary 
Scale (short form) NFER-Nelson, Windsor.

Elliot,C.D., Murrary,D.J., \& Pearson,L.S.(1978)BritishAbility

Scales. NFER-Nelson Publishing Company, Windsor.

Gathercole,S. \& Baddeley,A.D. (1993) Working Memory and Language. Hove: Lawrence Erlbaum Associates

Guralnick,M.J. (1990) Social competence and early intervention. Journal of Early Intervention, 14, 3-14.

Halford,G.S. \& Wilson,W.H. (1980) A category theory approach to cognitive development.Cognitive Psychology, 12, 356-411.

Herriot,P. \& Cox,A.M. (1971) Subjective organisation and clustering in the free-recall of intellectually -subnormal children. American Journal of Mental Deficiency, 75, 311-342. Hulme,C., \& Mackenzie,S. (1992) Working Memory and severe learning difficulties. Lawrence Erlbaum Associates, Publishers, Hove (UK).

McCarthy,D. (1972) McCarthy Scales of Children's Abilities. The Psychological Corporation, New York, NY.10017. Mackenzie,S., \& Hulme,C. (1987) Memory span development in Down's syndrome, severely subnormal and normal subjects. Cognitive Neuropsychology, 4 (3), 303-319.

Marcell,M.M., \& Armstrong,V. (1982) Auditory and visual sequential memory of Down Syndrome and non-retarded children. American Journal of Mental Deficiency, 87 (1), 8695.

Nicholson,R., Fawcett,A., \& Baddeley,A.D. (1991) Working memory and dyslexia. Unpublished paper. Presented at the International Conference on Memory, Lancaster, UK.

Raine,A., Hulme,C., Chadderton,H., \& Bailey,P. (1991) Verbal short-term memory span in speech disordered children: Implications for articulatory coding in short-term memory. Child Development, 62, 415-423.

Address for correspondence: Irene Broadley,

Department of Educational Psychology,

University of Southampton, Highfield,

Southampton, SO9 $5 \mathrm{NH}$, U.K.

\section{Third European Down Syndrome Conference \\ Dublin \\ 23 - 26 August 1995}

This conference for parents and professionals is organised by the Down Syndrome Association of Ireland, under the auspices of the European Down Syndrome Association (EDSA).

\section{Theme}

Towards an Inclusive Society implies a two-way journey: Society coming to meet people with Down syndrome; People with Down syndrome moving towards this welcoming community.

Our aim in the Conference is to look at ways to help people with Down syndrome more easily make their part of the journey to inclusion - to make them more ready to participate in the inclusive society.

\section{Subjects for discussion}

- Speech and language development

- Genetics - Effects of radiation

- Integration into society at all levels

- Employment - Second and third level education

- Health and nutrition - Obesity

\section{Social programme}

A wide-ranging social programme will be on offer during the Congress providing an opportunity for delegates and their families to enjoy the entertainment and leisure facilities in Dublin.

For further information, please contact:

Third European Down Syndrome Conference

10 Hagan Lane

Lad Lane

Dublin 2

IRELAND

Tel: 35316618904 Fax: 35316785047 